\title{
Response Rates and Representativeness: A Benchmark Comparison of the General Social Surveys to the American Community Surveys, 2012-2018*
}

\author{
Stephen L. Morgan \\ Johns Hopkins University

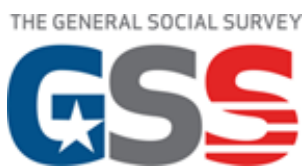

GSS Methodological Report No. 131

March 2020

* I thank Mike Davern, Jeremy Freese, and Tom Smith for their comments and suggestions. This research was supported by funds from the National Science Foundation (Awards \#SES-1458922 and \#SES-1851332). 


\section{INTRODUCTION}

The response rate for the General Social Survey (GSS) declined in 2016 and 2018 more than the GSS Board of Overseers expected. After the GSS moved to a full probability sample in 1975, the response rate had varied within a typical range of 75 to 79 percent for the next 23 years, with one year above 80 percent (82.4 in 1993) and a few below 75 percent (e.g., 73.5 in 1978 and 73.9 in 1990). From 2000 to 2012, the response rate then settled into a new equilibrium, moving between 70 and 71 percent for seven biennial surveys in a row. However, after a slight decline in 2014 to 69.2 percent, the response rate then fell abruptly to 61.3 percent in 2016. In 2018, it fell again, but by a more modest amount to 59.5 percent. $^{1}$

The reasons for the recent declines are not fully understood, and research with auxiliary data and other surveys may be able to provide additional clarity in the future. In the meantime, I offer this report to promote transparency and reassurance. On the one hand, the GSS is fighting the same non-response headwind that other national surveys confront (see Czajka and Beyler 2016), and thus there is reason to be concerned. On the other hand, the problem is not so acute that a decline in the demographic representativeness of the GSS is yet apparent. This overall conclusion is based on a comparison of the realized demographic composition of the GSS and the US Census Bureau's American Community Survey (ACS).

\section{THE ACS AS A BENCHMARK}

The ACS is a plausible benchmark for the GSS because it is accurate and can be aligned with the target population of the GSS. The Census Bureau samples more than 3.5 million households each year for the ACS. In addition to securing a high response rate, the Census Bureau uses population estimates from multiple sources and models when curating the ACS data for release. Accordingly, the ACS data analyzed in this report - the 2012, 2014, 2016, and 2018 Public Use Microdata Samples (PUMS) - warrant inference to the ACS target population with a high degree of expected accuracy.

\section{ACS Response Rates and the GSS in Comparison}

Table 1 (see next page) presents the ACS response rates for the four years analyzed in this report, and it shows that the ACS response rate declined from 97.3 percent in 2012 to 92.0 percent in 2018. ${ }^{2}$ While the increase in the refusal rate is the largest source of the decline, most other reasons for non-response increased in prevalence as well. Thus, the ACS has been affected by the same non-response headwind that has confronted other national surveys.

\footnotetext{
${ }^{1}$ See Appendix Table A.8 of Smith et al. (2019, page 3189) for additional detail, including sample sizes. The abruptness of the 2016 decline was unexpected, in part, because the GSS response rate held up well between 2000 and 2012 while other surveys were experiencing regular declines (see Czajka and Beyler 2016, Figure III.1).

${ }^{2}$ From 2000 through 2018, the ACS response rate averaged 95.9 percent. Table 1 is drawn from the Census Bureau's table for all ACS years; see

https://www.census.gov/acs/www/methodology/sample-size-and-data-quality/response-rates/).
} 
Table 1. ACS response rates and percent non-response by reason

\begin{tabular}{|c|c|c|c|c|c|c|c|c|c|}
\hline \multirow[t]{2}{*}{ Year } & $\begin{array}{l}\text { Response } \\
\text { rate } \\
\text { (percent) }\end{array}$ & & & & $\begin{array}{r}\operatorname{Re} \\
\text { non-resp }\end{array}$ & $\begin{array}{l}\text { son for } \\
\text { nse (percent) }\end{array}$ & & & \\
\hline & & Refusal & $\begin{array}{c}\text { Unable } \\
\text { to } \\
\text { locate }\end{array}$ & $\begin{array}{c}\text { No one } \\
\text { home }\end{array}$ & $\begin{array}{c}\text { Temporarily } \\
\text { absent }\end{array}$ & $\begin{array}{c}\text { Language } \\
\text { problem }\end{array}$ & $\begin{array}{c}\text { Insufficient } \\
\text { data }\end{array}$ & $\begin{array}{c}\text { Maximum } \\
\text { contact } \\
\text { attempts } \\
\text { reached }\end{array}$ & Other \\
\hline 2012 & 97.3 & 1.2 & 0 & 0.6 & 0.1 & 0 & 0.2 & $\mathrm{~N} / \mathrm{A}$ & 0.5 \\
\hline 2014 & 96.7 & 1.6 & 0 & 0.7 & 0.1 & 0 & 0.3 & $\mathrm{~N} / \mathrm{A}$ & 0.6 \\
\hline 2016 & 94.7 & 2.1 & 0 & 0.9 & 0.1 & 0.1 & 0.3 & 1.1 & 0.7 \\
\hline 2018 & 92.0 & 3.8 & 0.1 & 1.2 & 0.1 & 0.1 & 0.4 & 0.9 & 1.4 \\
\hline
\end{tabular}

Nonetheless, the ACS response rate remains much higher than other national surveys, in part because participation in the ACS is required by law. Consider the language on the relevant FAQ webpage for the US Census Bureau (https://ask.census.gov/):

\title{
Do I have to respond to the American Community Survey (ACS)?
}

\begin{abstract}
Yes. You are legally obligated to answer all the questions, as accurately as you can. The relevant laws are Title 18 U.S.C Section 3571 and Section 3559, which amends Title 13 U.S.C. Section 221.

Your answers are important. As part of a sample, you represent many other people. Find out how each question helps your community, your state, and the federal government in questions on the form and why we ask.
\end{abstract}

Similar language is included on the outside of the initial invitation envelope, as well as the enclosed letter and brochure (and then also for up to four additional mailings over the next five weeks). However conveyed, the Census Bureau's internal research shows that the legal requirement contributes to the high response rate of the ACS. ${ }^{3}$ Even so, the requirement did not prevent the decline shown in Table 1.

In contrast, participation in the GSS is voluntary, and it represents a much more substantial commitment of time. The median interview time for the 2018 GSS was 120 minutes, and 19 percent of interviews took at least 150 minutes, which is much more than the 40 minutes required to respond to the ACS. ${ }^{4}$ For the GSS, NORC's field staff must expend considerable effort to gain cooperation, while fully disclosing the amount of time required to sit for a complete interview. In 2018, the median number of contact attempts before securing a complete interview was 7 , and one interview was secured only after 44 contact attempts. ${ }^{5}$

\footnotetext{
${ }^{3}$ See National Academy of Sciences (2019) for details of communications as of 2018 as well as experimental results that demonstrate that softening the language of "required by law" leads to lower response rates (see Table 3.6). ${ }^{4}$ The Census Bureau's estimate for the time required to complete the ACS is 40 minutes (see Robins et al. 2016). ${ }^{5}$ I have been unable to locate a similar summary of contact attempts for the ACS, but the source for Table 1 suggests that stopping rules exist that define maxima for alternative completion mechanisms. Respondent burden, related to contact attempts, has been a topic of research (see Griffin, Slud, and Erdman 2015).
} 
Finally, the ACS allows any individual resident in the household to respond to the survey on behalf of the household. In contrast, for the GSS, a single adult is chosen as the potential GSS respondent, based on a selection method that mimics random selection from the household roster of adults. No other adult from the household can fill in for the selected individual in order to boost the response rate of the GSS. The ACS avoids this additional challenge, and thus its response rate is higher. ${ }^{6}$

\section{Aligning the ACS to the GSS Target Population}

The key question for this report is whether the recent decline in the GSS response rate has compromised the quality of the GSS data by the criterion of demographic representativeness, assessed using the ACS as a plausible benchmark. To enable such a benchmarked evaluation, the ACS sample must be aligned to the GSS target population, which is narrower. Prior to 2006, the target population of the GSS was all English-speaking individuals, at least 18 years old, living at non-institutional residential addresses in the US. Following the development of a Spanish language questionnaire, the target population of the 2006 GSS and more recent years became all English-speaking and Spanish-speaking individuals, at least 18 years old, living at non-institutional residential addresses in the US. Thus, the GSS target population for the years analyzed in this report excludes individuals living in institutionalized group quarters as well as individuals who are unable to take a survey in English or Spanish (e.g., monolingual Mandarin speakers resident in the US).

It is not possible to perfectly align the ACS with the target population of the GSS. While excluding the ACS group quarters sample is straightforward, the main challenge is the GSS inclusion pattern that arises from having survey instruments only in English and Spanish. For the analysis in this report, I utilized the ACS measures for language spoken in the home and ability to speak English in order to identify and then drop a small percentage of the ACS sample that approximates the non-English-and-non-Spanish-speaking population. I know of no way to assess the effectiveness of this ACS sample trimming in order to align it with the GSS target population.

\section{ACS ESTIMATES}

Tables 2 and 3 (see the next two pages) provide benchmark estimates from the ACS, as estimated subpopulation percentages of the ACS sample, when aligned with the target population of the GSS (see above). For example, the first column of Table 2 reports ACS benchmark estimates of the composition of the 2012 GSS target population. The first two numbers are 51.67 percent female and 15.05 percent Hispanic. These are the numbers that the GSS attempts to estimate with a sample that is approximately $1 / 1000^{\text {th }}$ the size of the ACS.

\footnotetext{
${ }^{6}$ In other words, the response rate for the ACS is a household-level response rate, boosted above individual-specific willingness by allowing anyone within the household to respond to the survey. The response rate for the GSS, and other similar surveys, is for specific individuals within households.
} 
Table 2. Estimates of subpopulation percentages from the 2012 and 2014 American Community Surveys

\begin{tabular}{|c|c|c|c|c|}
\hline & \multicolumn{2}{|c|}{2012} & \multicolumn{2}{|c|}{2014} \\
\hline Female & \multicolumn{2}{|c|}{51.67} & \multicolumn{2}{|c|}{51.66} \\
\hline Hispanic & \multicolumn{2}{|c|}{15.05} & \multicolumn{2}{|c|}{15.53} \\
\hline Age 18-24 & \multicolumn{2}{|c|}{12.21} & \multicolumn{2}{|c|}{11.98} \\
\hline Age 25-34 & \multicolumn{2}{|c|}{17.84} & \multicolumn{2}{|c|}{17.97} \\
\hline Age 35-49 & \multicolumn{2}{|c|}{26.37} & \multicolumn{2}{|c|}{25.48} \\
\hline Age 50-69 & \multicolumn{2}{|c|}{31.73} & \multicolumn{2}{|c|}{32.26} \\
\hline Age 70+ & \multicolumn{2}{|c|}{11.86} & \multicolumn{2}{|c|}{12.32} \\
\hline Less than HS or GED & \multicolumn{2}{|c|}{16.78} & \multicolumn{2}{|c|}{16.22} \\
\hline HS Diploma & \multicolumn{2}{|c|}{24.31} & \multicolumn{2}{|c|}{24.07} \\
\hline Some college & \multicolumn{2}{|c|}{31.40} & \multicolumn{2}{|c|}{31.26} \\
\hline Bachelor's degree & \multicolumn{2}{|c|}{17.57} & \multicolumn{2}{|c|}{18.01} \\
\hline Graduate & \multicolumn{2}{|c|}{9.94} & \multicolumn{2}{|c|}{10.44} \\
\hline \multirow[t]{2}{*}{ US Citizen } & \multicolumn{2}{|c|}{92.14} & \multicolumn{2}{|c|}{92.23} \\
\hline & Non-Hispanic & Hispanic & Non-Hispanic & Hispanic \\
\hline White alone & 66.85 & 9.96 & 65.82 & 10.35 \\
\hline White plus & 68.03 & 10.39 & 67.11 & 10.78 \\
\hline Black alone & 11.49 & 0.31 & 11.68 & 0.29 \\
\hline Black plus & 11.96 & 0.45 & 12.21 & 0.43 \\
\hline AIAN alone & 0.11 & 0.06 & 0.10 & 0.06 \\
\hline AIAN plus & 1.25 & 0.27 & 1.24 & 0.30 \\
\hline Asian alone & 4.22 & 0.06 & 4.48 & 0.05 \\
\hline Asian plus & 4.73 & 0.13 & 5.03 & 0.12 \\
\hline NHPI alone & 0.15 & 0.01 & 0.15 & 0.01 \\
\hline NHPI plus & 0.13 & 0.02 & 0.14 & 0.02 \\
\hline Other alone & 0.16 & 4.05 & 0.17 & 4.16 \\
\hline Other plus & 0.26 & 4.35 & 0.25 & 4.44 \\
\hline
\end{tabular}

Source: 2012 and 2014 PUMS data files of the American Community Surveys

Notes: $N=2,263,974$ in 2012. $N=2,299,569$ in 2014. The ACS sample was restricted to respondents aged 18 or older, resident in housing units rather than group quarters, and assessed as English or Spanish speakers (based on language spoken in the home and reported ability to speak English). All estimates are weighted, using the ACS weight variable pwgtp. Standard errors are not presented because they are exceedingly small and repetitive (as 0.02 or 0.03 ).

The ACS labels for the categories are Hispanic for "Spanish/Hispanic/Latino," Black for "Black or African American," AIAN for "American Indian and/or Alaska Native," NHPI for "Native Hawaiian or Other Pacific Islander," and Other for "Some Other Race." "Alone" denotes selection of a single race category, and "plus" denotes multiple race selections (the focal race category along with at least one other). For this reason, individuals can be in more than one cell for the bottom panel. An individual identified as both White and Asian, for example, would appear in both "White plus" and "Asian plus." 
Table 3. Estimates of subpopulation percentages from the 2016 and 2018 American Community Surveys

\begin{tabular}{|c|c|c|c|c|}
\hline & \multicolumn{2}{|c|}{2016} & \multicolumn{2}{|c|}{2018} \\
\hline Female & \multicolumn{2}{|c|}{51.58} & \multicolumn{2}{|c|}{51.56} \\
\hline Hispanic & \multicolumn{2}{|c|}{15.94} & \multicolumn{2}{|c|}{16.54} \\
\hline Age 18-24 & \multicolumn{2}{|c|}{11.52} & \multicolumn{2}{|c|}{11.15} \\
\hline Age $25-34$ & \multicolumn{2}{|c|}{18.11} & \multicolumn{2}{|c|}{18.25} \\
\hline Age 35-49 & \multicolumn{2}{|c|}{25.08} & \multicolumn{2}{|c|}{24.85} \\
\hline Age 50-69 & \multicolumn{2}{|c|}{32.53} & \multicolumn{2}{|c|}{32.05} \\
\hline Age 70+ & \multicolumn{2}{|c|}{12.76} & \multicolumn{2}{|c|}{13.69} \\
\hline Less than HS or GED & \multicolumn{2}{|c|}{15.59} & \multicolumn{2}{|c|}{14.67} \\
\hline HS Diploma & \multicolumn{2}{|c|}{23.73} & \multicolumn{2}{|c|}{23.65} \\
\hline Some college & \multicolumn{2}{|c|}{30.90} & \multicolumn{2}{|c|}{30.56} \\
\hline Bachelor's degree & \multicolumn{2}{|c|}{18.80} & \multicolumn{2}{|c|}{19.45} \\
\hline Graduate & \multicolumn{2}{|c|}{10.99} & \multicolumn{2}{|c|}{11.67} \\
\hline \multirow[t]{2}{*}{ US Citizen } & \multicolumn{2}{|c|}{92.31} & \multicolumn{2}{|c|}{92.54} \\
\hline & Non-Hispanic & Hispanic & Non-Hispanic & Hispanic \\
\hline White alone & 65.00 & 10.40 & 63.93 & 10.91 \\
\hline White plus & 66.40 & 10.84 & 65.46 & 11.41 \\
\hline Black alone & 11.69 & 0.29 & 11.74 & 0.33 \\
\hline Black plus & 12.28 & 0.45 & 12.39 & 0.51 \\
\hline AIAN alone & 0.10 & 0.06 & 0.10 & 0.07 \\
\hline AIAN plus & 1.28 & 0.31 & 1.24 & 0.37 \\
\hline Asian alone & 4.70 & 0.06 & 4.99 & 0.06 \\
\hline Asian plus & 5.31 & 0.14 & 5.68 & 0.16 \\
\hline NHPI alone & 0.16 & 0.02 & 0.16 & 0.02 \\
\hline NHPI plus & 0.14 & 0.02 & 0.14 & 0.02 \\
\hline Other alone & 0.20 & 4.48 & 0.21 & 4.42 \\
\hline Other plus & 0.29 & 4.76 & 0.31 & 4.75 \\
\hline
\end{tabular}

Source: 2016 and 2018 PUMS data file of the American Community Surveys

Notes: $N=2,360,775$ in 2016. $N=2,414,823$ in 2018. See also the notes to Table 2. 
Standard errors are excluded from Tables 2 and 3 because they are exceedingly small and repetitive (based on ACS samples that are well in excess of two million cases; see notes to the tables for the Ns). For example, the point estimates for percent female and percent Hispanic in 2012 - 51.67 percent and 15.05 percent, respectively - have estimated standard errors that are 0.02 percent and 0.03 percent, respectively. In the remainder of this report, I will treat the numbers in Tables 2 and 3 as precisely estimated up to the first decimal place, after rounding (but still subject to the target population qualification noted above and systematic sources of total survey error for the ACS, which are not captured by standard errors).

Readers unwilling to adopt this position are welcome to interpret the percentages in Tables 2 and 3 using a general standard of plus-or-minus $2 \times 0.03$ percent (i.e., percent Hispanic within an interval of 14.99 to 15.11 for 2012). That is the typical margin of error for the benchmark estimates, and it results in movements in the rounded first decimal of plus or minus 0.1 percent, such as 15.0 to 15.1 for percent Hispanic in 2012.

Most estimated percentages presented in Tables 2 and 3 are straightforward, but the cross-classifications of rates of Hispanic ethnicity by racial categories in the bottom panel of each table require more explanation. Note first that each ACS year is divided into two columns based on the ACS question on Hispanic ethnicity/origin that precedes the ACS question on racial self-identification: ${ }^{7}$

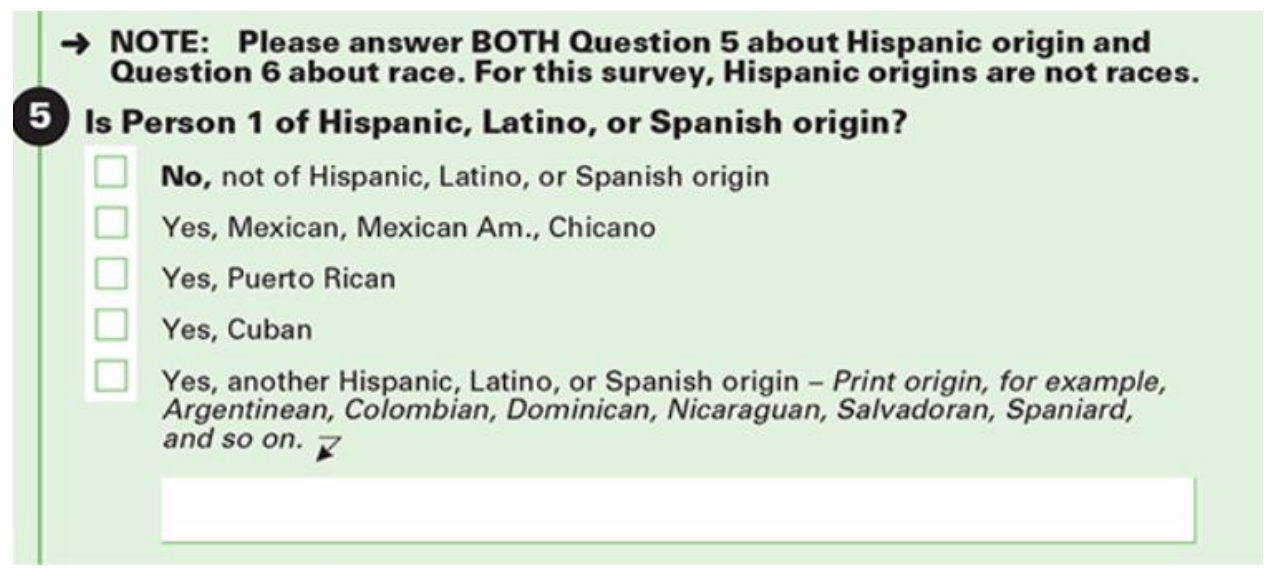

Note especially that for question 5, the household respondent is informed, "NOTE: Please answer BOTH Question 5 about Hispanic origin and Question 6 about race. For this survey, Hispanic origins are not races." Following question 5, racial categories are then offered in a subsequent question 6 with the ACS instruction, "Mark $(X)$ one or more boxes."

\footnotetext{
7 The images of the 2018 form can be found at: https://www2.census.gov/programssurveys/acs/methodology/questionnaires/2018/quest18.pdf.
} 


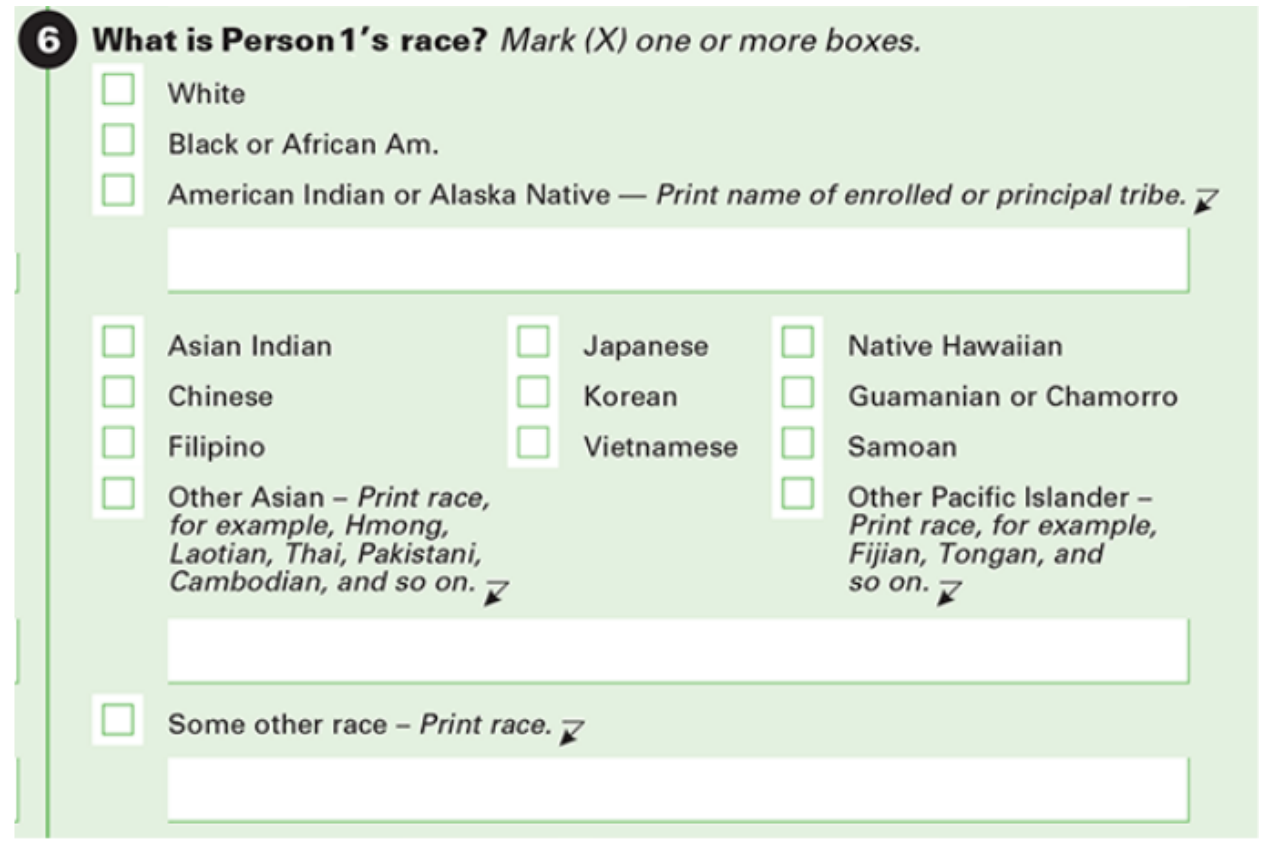

True to the words of the NOTE for question 5, Hispanic ethnicity/origin is not offered as a racial category for question 6 . Thus, if respondents feel that their Hispanic ethnicity/origins are "racial" in a way that conforms to their own conception of race, they are encouraged to abandon any such conception of race. If they are unwilling to do so, then they can evade the instructions from question 5, when completing question 6, and write in the last free-response box for question 6 an indication that they consider their type of Hispanic identification to be a racial identification. They can also satisfice and mark the checkbox without writing anything in the box.

It should also be noted, again, that the ACS uses a single household respondent to provide responses for all household members. As a result, many racial identities are reported by proxy because ACS household respondents must report their understandings of each household member's racial identity. For the GSS estimates below, only the GSS respondent's racial identification is available and thus analyzed, and this represents a slight measurement difference which must be incorporated in the interpretations that follow. ${ }^{8}$

After the data are collected, the Census Bureau codes the responses provided into a series of separate subpopulations for the ACS PUMS. The categorized identities and the abbreviated labels I have chosen for Tables 2 and 3 include Black for "Black or African American," AIAN for "American Indian and/or Alaska Native," NHPI for "Native Hawaiian or Other Pacific Islander," and Other for "Some Other Race."

\footnotetext{
8 Although the GSS collects proxy reports for some characteristics of spouses (and cohabiting partners), the GSS did not collect proxy reports of ethnic-racial identity for any household members during the years analyzed in this report. As a result, it is not possible to reduce the measurement difference between the ACS and the GSS by including proxy reports of ethnic-racial identity for all adults in GSS households.
} 
The qualifier "alone" denotes selection of a single race category, and the qualifier "plus" denotes multiple race selections. Because of the "alone" and "plus" variants for each group, individuals can be in more than one subpopulation for the bottom panel. For example, an individual who is identified as "White" is included in both "White alone" and "White plus." An individual who is identified as both White and Asian is included in both "White plus" and "Asian plus." Overall, the sum of the "alone" categories is less than 100 percent, and the sum of the "plus" categories is greater than 100 percent.

As can be seen in Tables 2 and 3, after "White alone" and "White plus," the next two largest categories in the Hispanic columns are "Other alone" and "Other plus." The standard interpretation of data such as these collected by the Census Bureau is that these Hispanic and "Other race" individuals are predominantly those who identify as having Hispanic ethnicity/origins as well as a personal conception of race that confers racial identity to Hispanic ethnicity/origins. Thus, these individuals are not identified with the other response options for race, most notably White, Black, and American Indian.

\section{COMPARISON ESTIMATES FROM THE GSS}

The key topic of investigation for this report is whether any differences between the ACS and GSS in their demographic representativeness emerged (or increased) after the GSS response rate fell abruptly in 2016. Any such increases could be attributable to the decline in the GSS response rate.

For comparison to the ACS benchmarks above, Tables 4 through 7 (see the next eight pages) provide estimates of subpopulation percentages from the GSS, as percentages of GSS respondents in each year. 9 The data are weighted by NORC's recommended GSS weight, wtssnr. Each estimated percentage is accompanied by a standard error and a corresponding 95percent confidence interval. The standard errors are design-adjusted, using the GSS variables vstrat and vpsu with the svy estimation commands of Stata.

\footnotetext{
${ }^{9}$ An alternative estimation strategy would be to attempt to estimate raw sizes of the subpopulations, and then to compare these estimates for the ACS and GSS. The advantage of doing so would be that the estimates would not then be a function of compositional shifts within the respective studies. I decided not to pursue this strategy because (1) GSS users are inherently interested in the demographic composition of the GSS, and so the form of comparison I have chosen is likely the one that would be of interest to those with concerns about the consequences of response rates for demographic representativeness; (2) benchmark-type comparisons of sample composition have been used to promote reassurance in the past for the GSS (e.g., Smith 1978, 1993); (3) in this case, as shown below, the compositional differences are small enough that the overall conclusions would be the same.
} 
Table 4. Estimates of subpopulation percentages from the 2012 General Social Survey

\begin{tabular}{|c|c|c|c|c|}
\hline & Percent & Standard error & \multicolumn{2}{|c|}{ Confidence interval } \\
\hline \multicolumn{5}{|c|}{ All respondents } \\
\hline Female & 53.71 & 1.46 & 50.80 & 56.62 \\
\hline Hispanic & 15.08 & 1.43 & 12.23 & 17.93 \\
\hline Age 18-24 & 11.75 & 1.02 & 9.70 & 13.79 \\
\hline Age 25-34 & 19.24 & 1.16 & 16.92 & 21.57 \\
\hline Age $35-49$ & 27.63 & 1.17 & 25.30 & 29.96 \\
\hline Age 50-69 & 30.52 & 1.32 & 27.89 & 33.15 \\
\hline Age 70+ & 10.87 & 0.76 & 9.34 & 12.39 \\
\hline Less than HS & 14.62 & 1.00 & 12.62 & 16.61 \\
\hline HS Diploma or GED & 48.73 & 1.26 & 46.21 & 51.24 \\
\hline Some college & 8.32 & 0.70 & 6.92 & 9.72 \\
\hline Bachelor's degree & 18.65 & 1.14 & 16.39 & 20.92 \\
\hline Graduate & 9.68 & 0.83 & 8.02 & 11.35 \\
\hline US Citizen & 93.05 & 0.80 & 91.45 & 94.64 \\
\hline \multicolumn{5}{|c|}{ Non-Hispanic respondents only } \\
\hline White alone & 61.24 & 1.74 & 57.76 & 64.72 \\
\hline White plus & 65.21 & 1.75 & 61.73 & 68.69 \\
\hline Black alone & 12.53 & 1.23 & 10.08 & 14.97 \\
\hline Black plus & 14.88 & 1.29 & 12.31 & 17.46 \\
\hline AIAN alone & 0.82 & 0.43 & 0.00 & 1.67 \\
\hline AIAN plus & 4.24 & 0.68 & 2.89 & 5.58 \\
\hline Asian alone & 4.00 & 0.83 & 2.33 & 5.66 \\
\hline Asian plus & 4.84 & 0.85 & 3.14 & 6.54 \\
\hline NHPI alone & 0.28 & 0.16 & 0.00 & 0.61 \\
\hline NHPI plus & 0.42 & 0.19 & 0.03 & 0.80 \\
\hline Other alone & 0.78 & 0.29 & 0.19 & 1.36 \\
\hline Other plus & 0.87 & 0.28 & 0.31 & 1.44 \\
\hline Hispanic race alone & 0.00 & & & \\
\hline Hispanic race plus & 0.00 & & & \\
\hline
\end{tabular}


Table 4 (Continued). Estimates of subpopulation percentages from the 2012 General Social Survey

\begin{tabular}{|c|c|c|c|c|}
\hline & Percent & Standard error & Confidenc & e interval \\
\hline \multicolumn{5}{|c|}{ Hispanic respondents only } \\
\hline White alone & 7.91 & 1.02 & 5.87 & 9.95 \\
\hline White plus & 9.33 & 1.13 & 7.08 & 11.58 \\
\hline Black alone & 0.22 & 0.12 & 0.00 & 0.46 \\
\hline Black plus & 0.53 & 0.18 & 0.18 & 0.89 \\
\hline AIAN alone & 0.00 & & & \\
\hline AIAN plus & 0.43 & 0.15 & 0.14 & 0.73 \\
\hline Asian alone & 0.00 & & & \\
\hline Asian plus & 0.41 & 0.19 & 0.04 & 0.79 \\
\hline NHPI alone & 0.00 & & & \\
\hline NHPI plus & 0.15 & 0.15 & 0.00 & 0.43 \\
\hline Other alone & 0.13 & 0.08 & 0.00 & 0.30 \\
\hline Other plus & 0.17 & 0.09 & 0.00 & 0.36 \\
\hline Hispanic race alone & 4.92 & 0.69 & 3.53 & 6.30 \\
\hline Hispanic race plus & 6.03 & 0.85 & 4.33 & 7.72 \\
\hline
\end{tabular}

Source: 2012 General Social Survey

Notes: $N$ varies from 1,974 for the female dummy to 1,960 for the race dummies. Data are weighted by wtssnr.

Hispanic respondents are measured by a census-based question placed on the GSS survey instrument: "Are you Spanish, Hispanic, or Latino/Latina?" The "Hispanic race" category is based on a follow-up response to the race question, "What is your race? Indicate one or more races that you consider yourself to be." If the respondent indicates "Some other race" for this question, the respondent is prompted with "Please name." While the ACS places all such respondents in its "Other race" category, the GSS breaks these named other races into Hispanic and a residual "other" category. Finally, "alone" and "plus," are defined the same in this table as for the ACS results in prior tables. 
Table 5. Estimates of subpopulation percentages from the 2014 General Social Survey

\begin{tabular}{|c|c|c|c|c|}
\hline & Percent & Standard error & \multicolumn{2}{|c|}{ Confidence interval } \\
\hline \multicolumn{5}{|c|}{ All respondents } \\
\hline Female & 54.51 & 1.21 & 52.08 & 56.93 \\
\hline Hispanic & 16.94 & 1.36 & 14.21 & 19.66 \\
\hline Age 18-24 & 9.29 & 0.82 & 7.67 & 10.92 \\
\hline Age $25-34$ & 19.09 & 1.05 & 16.98 & 21.19 \\
\hline Age 35-49 & 25.27 & 0.96 & 23.35 & 27.19 \\
\hline Age 50-69 & 34.59 & 1.20 & 32.19 & 36.99 \\
\hline Age 70+ & 11.76 & 0.77 & 10.22 & 13.30 \\
\hline Less than HS & 12.71 & 0.84 & 11.04 & 14.38 \\
\hline HS Diploma or GED & 51.01 & 1.20 & 48.63 & 53.40 \\
\hline Some college & 7.32 & 0.55 & 6.22 & 8.43 \\
\hline Bachelor's degree & 18.61 & 1.11 & 16.40 & 20.82 \\
\hline Graduate & 10.34 & 0.76 & 8.83 & 11.85 \\
\hline US Citizen & 92.77 & 0.72 & 91.33 & 94.21 \\
\hline \multicolumn{5}{|c|}{ Non-Hispanic respondents only } \\
\hline White alone & 60.88 & 1.68 & 57.53 & 64.23 \\
\hline White plus & 65.76 & 1.73 & 62.30 & 69.22 \\
\hline Black alone & 12.73 & 1.18 & 10.37 & 15.08 \\
\hline Black plus & 14.41 & 1.20 & 12.01 & 16.80 \\
\hline AIAN alone & 0.37 & 0.17 & 0.02 & 0.71 \\
\hline AIAN plus & 4.32 & 0.57 & 3.19 & 5.45 \\
\hline Asian alone & 3.13 & 0.51 & 2.11 & 4.16 \\
\hline Asian plus & 4.10 & 0.66 & 2.78 & 5.41 \\
\hline NHPI alone & 0.02 & 0.02 & 0.00 & 0.05 \\
\hline NHPI plus & 0.10 & 0.06 & 0.00 & 0.22 \\
\hline Other alone & 0.24 & 0.12 & 0.01 & 0.48 \\
\hline Other plus & 0.48 & 0.16 & 0.16 & 0.81 \\
\hline Hispanic race alone & 0.00 & & & \\
\hline Hispanic race plus & 0.00 & & & \\
\hline
\end{tabular}

Continued on next page: 
Table 5 (Continued). Estimates of subpopulation percentages from the 2014 General Social Survey

\begin{tabular}{|c|c|c|c|c|}
\hline & Percent & Standard error & Confiden & e interval \\
\hline \multicolumn{5}{|c|}{ Hispanic respondents only } \\
\hline White alone & 8.82 & 0.95 & 6.94 & 10.71 \\
\hline White plus & 10.04 & 0.99 & 8.05 & 12.02 \\
\hline Black alone & 0.33 & 0.13 & 0.06 & 0.60 \\
\hline Black plus & 0.52 & 0.17 & 0.19 & 0.85 \\
\hline AIAN alone & 0.41 & 0.17 & 0.06 & 0.76 \\
\hline AIAN plus & 0.91 & 0.30 & 0.32 & 1.51 \\
\hline Asian alone & 0.00 & & & \\
\hline Asian plus & 0.14 & 0.08 & 0.00 & 0.29 \\
\hline NHPI alone & 0.27 & 0.17 & 0.00 & 0.62 \\
\hline NHPI plus & 0.31 & 0.18 & 0.00 & 0.66 \\
\hline Other alone & 0.18 & 0.10 & 0.00 & 0.39 \\
\hline Other plus & 0.29 & 0.12 & 0.05 & 0.52 \\
\hline Hispanic race alone & 5.42 & 0.71 & 4.00 & 6.83 \\
\hline Hispanic race plus & 6.35 & 0.79 & 4.77 & 7.93 \\
\hline
\end{tabular}

Source: 2014 General Social Survey

Notes: $N$ varies from 2,538 for the female dummy to 2,510 for the race dummies. See also the Notes for Table 4 . 
Table 6. Estimates of subpopulation percentages from the 2016 General Social Survey

\begin{tabular}{|c|c|c|c|c|}
\hline & Percent & Standard error & \multicolumn{2}{|c|}{ Confidence interval } \\
\hline \multicolumn{5}{|c|}{ All respondents } \\
\hline Female & 54.80 & 1.07 & 52.67 & 56.93 \\
\hline Hispanic & 14.41 & 1.46 & 11.48 & 17.33 \\
\hline Age 18-24 & 10.28 & 0.79 & 8.70 & 11.86 \\
\hline Age 25-34 & 17.83 & 0.97 & 15.90 & 19.76 \\
\hline Age 35-49 & 25.05 & 1.01 & 23.04 & 27.06 \\
\hline Age 50-69 & 34.84 & 1.14 & 32.57 & 37.11 \\
\hline Age 70+ & 12.01 & 0.75 & 10.50 & 13.51 \\
\hline Less than HS & 11.69 & 0.91 & 9.88 & 13.50 \\
\hline HS Diploma or GED & 51.90 & 1.28 & 49.35 & 54.45 \\
\hline Some college & 7.45 & 0.56 & 6.33 & 8.57 \\
\hline Bachelor's degree & 18.45 & 1.01 & 16.43 & 20.47 \\
\hline Graduate & 10.51 & 0.73 & 9.07 & 11.96 \\
\hline US Citizen & 94.24 & 0.70 & 92.84 & 95.65 \\
\hline \multicolumn{5}{|c|}{ Non-Hispanic respondents only } \\
\hline White alone & 60.64 & 1.72 & 57.20 & 64.08 \\
\hline White plus & 65.64 & 1.64 & 62.36 & 68.92 \\
\hline Black alone & 13.85 & 1.21 & 11.44 & 16.26 \\
\hline Black plus & 16.89 & 1.36 & 14.17 & 19.61 \\
\hline AIAN alone & 0.95 & 0.33 & 0.29 & 1.61 \\
\hline AIAN plus & 5.85 & 0.60 & 4.66 & 7.05 \\
\hline Asian alone & 3.04 & 0.43 & 2.19 & 3.89 \\
\hline Asian plus & 4.06 & 0.45 & 3.16 & 4.96 \\
\hline NHPI alone & 0.10 & 0.06 & 0.00 & 0.22 \\
\hline NHPI plus & 0.29 & 0.10 & 0.09 & 0.49 \\
\hline Other alone & 0.32 & 0.11 & 0.09 & 0.54 \\
\hline Other plus & 0.60 & 0.17 & 0.26 & 0.94 \\
\hline Hispanic race alone & 0.00 & & & \\
\hline Hispanic race plus & 0.11 & 0.07 & 0.00 & 0.24 \\
\hline
\end{tabular}

Continued on next page: 
Table 6 Continued). Estimates of subpopulation percentages from the 2016 General Social Survey

\begin{tabular}{|c|c|c|c|c|}
\hline & Percent & Standard error & Confiden & e interval \\
\hline \multicolumn{5}{|c|}{ Hispanic respondents only } \\
\hline White alone & 7.74 & 1.02 & 5.71 & 9.78 \\
\hline White plus & 8.65 & 1.08 & 6.48 & 10.81 \\
\hline Black alone & 0.73 & 0.22 & 0.29 & 1.16 \\
\hline Black plus & 1.05 & 0.26 & 0.53 & 1.57 \\
\hline AIAN alone & 0.48 & 0.18 & 0.12 & 0.84 \\
\hline AIAN plus & 1.18 & 0.29 & 0.61 & 1.76 \\
\hline Asian alone & 0.21 & 0.15 & 0.00 & 0.51 \\
\hline Asian plus & 0.41 & 0.19 & 0.03 & 0.79 \\
\hline NHPI alone & 0.00 & & & \\
\hline NHPI plus & 0.00 & & & \\
\hline Other alone & 0.17 & 0.10 & 0.00 & 0.38 \\
\hline Other plus & 0.17 & 0.10 & 0.00 & 0.38 \\
\hline Hispanic race alone & 3.96 & 0.56 & 2.84 & 5.07 \\
\hline Hispanic race plus & 4.18 & 0.59 & 3.02 & 5.35 \\
\hline
\end{tabular}

Source: General Social Survey

Notes: $N$ varies from 2,867 for the female dummy to 2,843 for the race dummies. See also the Notes for Table 4. 
Table 7. Estimates of subpopulation percentages from the 2018 General Social Survey

\begin{tabular}{|c|c|c|c|c|}
\hline & Percent & Standard error & \multicolumn{2}{|c|}{ Confidence interval } \\
\hline \multicolumn{5}{|c|}{ All respondents } \\
\hline Female & 53.96 & 1.23 & 51.51 & 56.41 \\
\hline Hispanic & 16.12 & 1.50 & 13.13 & 19.10 \\
\hline Age 18-24 & 11.76 & 0.93 & 9.92 & 13.61 \\
\hline Age 25-34 & 19.18 & 1.12 & 16.96 & 21.40 \\
\hline Age 35-49 & 25.76 & 1.15 & 23.47 & 28.05 \\
\hline Age 50-69 & 31.27 & 1.03 & 29.22 & 33.32 \\
\hline Age 70+ & 12.03 & 0.76 & 10.53 & 13.54 \\
\hline Less than HS & 11.48 & 1.13 & 9.23 & 13.72 \\
\hline HS Diploma or GED & 49.25 & 1.30 & 46.66 & 51.84 \\
\hline Some college & 8.16 & 0.68 & 6.81 & 9.50 \\
\hline Bachelor's degree & 20.41 & 0.99 & 18.44 & 22.38 \\
\hline Graduate & 10.71 & 0.91 & 8.90 & 12.53 \\
\hline US Citizen & 93.45 & 0.86 & 91.75 & 95.16 \\
\hline \multicolumn{5}{|c|}{ Non-Hispanic respondents only } \\
\hline White alone & 60.15 & 1.82 & 56.52 & 63.78 \\
\hline White plus & 65.77 & 1.85 & 62.09 & 69.45 \\
\hline Black alone & 12.44 & 1.16 & 10.13 & 14.76 \\
\hline Black plus & 15.15 & 1.25 & 12.66 & 17.64 \\
\hline AIAN alone & 0.40 & 0.12 & 0.16 & 0.65 \\
\hline AIAN plus & 5.08 & 0.43 & 4.22 & 5.95 \\
\hline Asian alone & 3.22 & 0.49 & 2.25 & 4.19 \\
\hline Asian plus & 4.29 & 0.56 & 3.18 & 5.40 \\
\hline NHPI alone & 0.06 & 0.04 & 0.00 & 0.14 \\
\hline NHPI plus & 0.26 & 0.11 & 0.04 & 0.48 \\
\hline Other alone & 0.49 & 0.14 & 0.21 & 0.77 \\
\hline Other plus & 1.21 & 0.25 & 0.72 & 1.71 \\
\hline Hispanic race alone & 0.04 & 0.04 & 0.00 & 0.11 \\
\hline Hispanic race plus & 0.08 & 0.05 & 0.00 & 0.17 \\
\hline
\end{tabular}

Continued on next page: 
Table 7 (Continued). Estimates of subpopulation percentages from the 2018 General Social Survey

\begin{tabular}{|c|c|c|c|c|}
\hline & Percent & Standard error & Confiden & e interval \\
\hline \multicolumn{5}{|c|}{ Hispanic respondents only } \\
\hline White alone & 7.19 & 0.81 & 5.57 & 8.81 \\
\hline White plus & 8.53 & 0.91 & 6.72 & 10.34 \\
\hline Black alone & 0.37 & 0.15 & 0.08 & 0.66 \\
\hline Black plus & 0.68 & 0.24 & 0.20 & 1.16 \\
\hline AIAN alone & 0.35 & 0.18 & 0.00 & 0.70 \\
\hline AIAN plus & 0.74 & 0.26 & 0.22 & 1.25 \\
\hline Asian alone & 0.00 & & & \\
\hline Asian plus & 0.26 & 0.11 & 0.04 & 0.48 \\
\hline NHPI alone & 0.05 & 0.05 & 0.00 & 0.14 \\
\hline NHPI plus & 0.11 & 0.08 & 0.00 & 0.26 \\
\hline Other alone & 0.41 & 0.14 & 0.12 & 0.69 \\
\hline Other plus & 0.52 & 0.16 & 0.20 & 0.84 \\
\hline Hispanic race alone & 6.00 & 0.94 & 4.14 & 7.87 \\
\hline Hispanic race plus & 7.14 & 0.99 & 5.18 & 9.10 \\
\hline
\end{tabular}

Source: 2018 General Social Survey

Notes: $N$ varies from 2,348 for the female dummy to 2,318 for the race dummies. See also the Notes for Table 4 . 


\section{COMPARISONS OF DEMOGRAPHIC REPRESENTATIVENESS}

In this section, I will offer comparisons between the ACS and GSS that treat the ACS point estimates above in Tables 2 and 3 as truth, plus or minus one digit in the first decimal place (because their standard errors, as noted above, are usually 0.03 or less for each percentage). In addition, the ACS has a high degree of accuracy because it has a high response rate and is also calibrated using intercensal estimates of population totals developed by the Census Bureau.

A convenient method of comparison is to determine whether the ACS point estimates fall within the estimated 95-percent confidence intervals for the respective GSS point estimates. This is a reasonable approach because it delivers what a GSS analyst wants to know: Are the GSS point estimates too far from the ACS point estimates, given the range of variation one could reasonably expect from the GSS sample? ${ }^{10}$

Before offering detailed comparisons for the demographic characteristics, two general points should be framed:

1. The non-response adjusted sampling weight of the GSS, wtssnr, does not incorporate post-stratification to known or estimated population characteristics. ${ }^{11}$ Thus, any alignment of the GSS estimates in Tables 4 through 7 to the ACS benchmark estimates in Tables 2 and 3 arises (almost entirely) from the quality of the initial GSS sampling design, NORC's effort to gain cooperation from households to construct a household roster and select a respondent, and then, finally, NORC's capacity to convince the selected household respondent to complete the interview.

2. Some differences between the benchmark ACS estimates and the GSS estimates are attributable to the slight misalignment of their target populations, as explained above, and others to stable differences in measurement technique, as explained below where relevant.

\footnotetext{
${ }^{10}$ Another approach would be to (1) construct expected confidence intervals around the ACS point estimates for a sample of the size and design of the GSS and then (2) ask whether the GSS point estimates are contained within these intervals. This alternative approach is not readily feasible because the variance estimates for the ACS would have to mimic the exact design of the GSS realized in each year, which is a stratified sample with inherent clustering by geography that varies somewhat in each year because of segment selection (within the NORC national sampling design that was fixed from 2012 through 2018). One could simply transfer the GSS standard errors I have estimated to construct confidence intervals around the ACS point estimates, but that is then equivalent to the comparison method used in the main text, varying only by the direction of each evaluation.

11 The non-response component of the GSS weight wtssnr only accounts for slight variation in response rates across geographic sampling units, such that households in areas with high/low response rates are weighted downwards/upwards very slightly after data collection is concluded and raw GSS response rates can be calculated. For further explanation, see Appendix A of Smith et al. (2019).
} 


\section{Gender}

The GSS continues to underrepresent men by 2 to 3 percentage points, and this particular pattern of underrepresentation is longstanding and well known, apparently first analyzed for the GSS in an early methodological report by Tom W. Smith (see Smith 1979; see also Smith 1983). ${ }^{12}$ The reasons for the over-representation of women are not known with certainty, but the pattern is common for household surveys, like the GSS, where only one respondent per household is selected for inclusion in the sample. The leading candidate explanation is basic response propensity; men, on average, are less cooperative and more hostile, and they are also less likely to be present in the home. ${ }^{13}$ Most full population household surveys have this gender imbalance, and many correct for it with the use of post-stratification weights. For the GSS, the imbalance has been stable over the years (see Smith 2019), and thus the GSS has not adjusted for it (and simply recommended that GSS users model gender differences explicitly when studying social change). While there are good reasons for the GSS to consider post-stratification weighting in the future - and this is one of the main ones - the gender imbalance did not increase for 2016 and 2018. In fact, the imbalance was smallest in 2018 when the overall response rate was the lowest.

\section{Hispanic Ethnicity/Origin}

In all four years, the GSS performs well in representing respondents who indicate that they have Hispanic, Latino, or Spanish origins. The ACS benchmark estimates increase from 15.05 percent in 2012 to 16.54 in 2018. The GSS estimates move up and down because of sampling error - from 15.08 to 16.94, 14.41, and then 16.12 from 2012 to 2018. With standard errors between 1.36 and 1.50 percentage points, the confidence intervals around the GSS point estimates include the ACS benchmark estimates for all four years. In other words, the GSS estimates do not match the ACS estimates, but the differences are entirely consistent with the random variation that could be produced by sampling.

\section{Age}

The age structure of the GSS also matches the ACS benchmarks quite well. For the 20 comparisons (five estimates, over four years), the ACS point estimates fall within the GSS confidence intervals 17 times (with one miss each in 2014, 2016, and 2018). In 2018, for example, 13.69 percent of the ACS was age 70 or older. For the GSS, the corresponding percentage was lower at 10.71 with a standard error of 0.91 , yielding a 95-percent confidence interval of 10.53 to 13.54. Thus, the confidence interval just barely excludes the ACS estimate of 13.69. Overall, there is little or no evidence that the mismatches are greater in 2016 or 2018.

\footnotetext{
${ }^{12}$ Gender distributions do not vary much with geography, and thus the mild non-response adjustment embedded in NORC's weight, wtssnr, does not correct for the underrepresentation of men.

${ }^{13}$ Another potential explanation is that interviewers sometimes alter the Kish method of selecting the household respondent in a way that favors women (presumably, as an adaptation to gain a household's cooperation). See Kish (1965, section 11.3) for the respondent selection method that is used for the GSS and also Smith (1979) for an argument for why this was unlikely to be the case in the early years of the GSS.
} 


\section{Education}

Not all education categories can be easily aligned for the ACS and GSS because of how GEDs are handled and how "some college" is defined. The ACS collects this information in a single question while the GSS uses multiple questions. As a result, for some types of respondents there are systematic differences across all years that are attributable to measurement differences. However, for two categories where we have the most measurement consistency the percentage with a bachelor's degree but not a graduate degree and the percentage with a graduate degree - the ACS point estimates always fall within the GSS confidence intervals.

\section{Citizenship}

Especially given the political context of 2016 and 2018, there is reasonable concern that all surveys may be under-representing non-citizens among genuine residents in the US. Tables 2 through 7 show that the GSS matches the ACS quite well, with a close miss in 2016 (where the ACS percentage of 92.31 falls just below the confidence interval for the GSS of 92.84 to 95.65 ). For 2018, the ACS benchmark estimate of 92.5 percent falls near to the GSS estimate of 93.45 and well within the GSS confidence interval. Overall, it may be the case that both the GSS and the ACS under-represent non-citizens resident in the US. If so, they appear to do so by about the same amount from 2012 through 2018.

\section{Race}

The largest challenge for estimation is for the many categories defined by multiple options for race, crossed by Hispanic ethnicity/origin. These challenges are complicated by some meaningful measurement differences. First, the GSS limits racial self-identification to three choices only, which could lead to a very slightly lower percentage for each "plus" category. On the other hand, the GSS, because of its breadth and personal touch, may prompt more respondents to select multiple categories rather than satisfice to end the ACS experience as quickly as possible. In addition, the ACS uses proxy reports of the ethnic-racial identities of household members provided by the household respondent, which could lead to a lower rate of multiracial identity if the respondent is inclined to see other household members' racial identities as simpler than they are. ${ }^{14}$ Finally, as explained above, the GSS explicitly codes for Hispanic race in its final question (which the Census Bureau could do with its free-response box, but chooses not to; see the discussion of ACS question 6 above). A reasonable interpretation is that the "Hispanic" and "Other" race categories for the GSS, when summed together, are close to the broader "Other" race category for the ACS. (As discussed above, Hispanic ethnicity/origin is measured in much the same way for both the ACS and the GSS. Both surveys yield similar rates.)

\footnotetext{
14 There is some evidence from earlier years of the GSS that ethnicity based on questions about countries of origin is more detailed for self-reports than for proxy reports for spouses. Smith (1985:4) concluded, "It appears that respondents lack complete knowledge of the ethnic complexity and diversity of their partners (and therefore mention fewer ethnic backgrounds for their spouses)."
} 
With these measurement differences in mind, the GSS performs well across all points of comparison in the final two panels of Tables 4 through 7. All groups are represented as one would expect, with the variation between "plus" and "alone" a bit wider in the GSS probably because of measurement variation just discussed (and with the greater prominence of multiracial identification as non-Hispanic American Indian or Alaskan Native especially notable for the GSS). The GSS may under-represent Asian respondents, and this may have increased slightly in 2016 and 2018. Nonetheless, this pattern could result from a target population misalignment based on how the ACS sample was trimmed to English and Spanish speakers. Or it could be a non-response trend that suggests a growing need for Asian language versions of the GSS. We will know more when the 2020 data collection is complete.

\section{CONCLUSIONS}

My interpretation of the results presented in Tables 2 through 7 is that the 2016 GSS and 2018 GSS match the ACS benchmark estimates just as well as do the 2012 GSS and 2014 GSS. Although readers may wish to draw alternative conclusions, my interpretation is that the response-rate declines in 2016 and 2018 have not undermined the representativeness of the GSS, at least with respect to core demographic characteristics. It is possible that features of the joint distribution of attitudes and opinions have been more seriously compromised. If so, any substantial changes would be most likely for measured variables that have comparatively weak associations with core demographic characteristics as well as comparatively large net associations with non-response propensity.

The response-rate declines have, however, reduced the raw numbers of completed interviews, and otherwise increased recruitment costs. In combination, the cost of each completed interview for the GSS has increased considerably. For this reason, the cost implications of the response-rate declines are substantial and represent a growing challenge for the funding of the project. 


\section{References Cited}

Czajka, John L. and Amy Beyler. 2016. “Declining Response Rates in Federal Surveys: Trends and Implications." Mathematica Policy Research Reports, Mathematica Policy Research, Washington, DC.

Griffin, Deborah H., Eric V. Slud, and Chandra Erdman. 2015. “Reducing Respondent Burden in the American Community Survey's Computer Assisted Personal Visit Interviewing Operation - Phase 3 Results." American Community Survey Research and Evaluation Report Memorandum Series ACS14-RER-28-R1, US Census Bureau, Washington, DC.

Kish, Leslie. 1965. Survey Sampling. New York: Wiley.

National Academies of Sciences, Engineering, and Medicine. 2019. Improving the American Community Survey: Proceedings of a Workshop. Washington, DC: The National Academies Press. https://doi.org/10.17226/25387.

Robins, Cynthia, Darby Steiger, Jasmine Folz, Karen Stein, and Martha Stapleton. 2016. "American Community Survey Respondent Burden Testing, Final Briefing Report." American Community Survey Research and Evaluation Report Memorandum Series, ACS16-RER-16, US Census Bureau, Washington, DC.

Smith, Tom W. 1978. “Response Rates on the 1975-1978 General Social Surveys with Comparisons to the Omnibus Surveys of the Survey Research Center, 1972-1976." GSS Methodological Report No. 5, National Opinion Research Center, Chicago, Illinois.

Smith, Tom W. 1979. "Sex and the GSS: Nonresponse Differences." GSS Methodological Report No. 9, National Opinion Research Center, Chicago, Illinois.

Smith, Tom W. 2019[1979]. “Sex and the GSS: Nonresponse Differences - An Update." GSS Methodological Report No. 9a, National Opinion Research Center, Chicago, Illinois.

Smith, Tom W. 1983. “Using Temporary Refusals to Estimate Nonresponse Bias.” GSS Methodological Report No. 38, National Opinion Research Center, Chicago, Illinois.

Smith, Tom W. 1985. “An Analysis of the Accuracy of Spousal Reports.” GSS Methodological Report No. 35, National Opinion Research Center, Chicago, Illinois.

Smith, Tom W. 1993. “Notes on John Brehm, The Phantom Respondent: Opinion Surveys and Political Representation." GSS Methodological Report No. 79, National Opinion Research Center, Chicago, Illinois.

Smith, Tom W., Michael Davern, Jeremy Freese, and Stephen L. Morgan. 2019. General Social Surveys, 1972-2018, Cumulative Codebook. Chicago: NORC. 